\title{
WEIGHTS, MEASURES AND CURRENCY
}

Medieval weights and measures were standardised, but only up to a point, with many local variations and different usages for different commodities. Where the detail of these is important, the notes to the text give further information. The principal units are given below, with approximate metric equivalents for the main measure in each class.

\section{Liquid measure}

2 pints $=1$ quart; 4 pints $=1$ pottle; 8 pints $=1$ gallon

1 pint $=0.568$ litres

Dry capacity

4 pecks (pks) $=1$ bushel (bus.); 8 bushels $=1$ quarter (qr)

1 peck $=9.092$ litres

\section{Length}

12 inches (ins) $=1$ foot; 3 feet $=1$ yard; 1760 yards $=1$ mile

36 inches $=1$ verge, a cloth-yard; 45 inches $=1$ ell

1 yard $=0.914$ metres

\section{Weight}

16 ounces $(\mathrm{oz})$ avoirdupoids $=1$ pound $(\mathrm{lb}) ; 14$ pounds (lbs) $=1$ stone; 8 stones $=1$ hundredweight $(\mathrm{cwt})$. For weights in weys, see the notes.

1 pound $=0.454$ kilograms 


\section{Currency}

12 pence $(d)=1$ shilling $(s) ; 20$ shillings $=1$ pound $(£ 1=240 d)$. The penny was divided into 2 halfpence and 4 farthings. 1 mark was worth $13 s 4 d$, twothirds of $£ 1(160 d)$.

\section{Currency as weight}

The English royal household in the fourteenth century and early fifteenth century recorded the weight of plate using Tower pounds, expressed as pounds, shillings and pence, rather than Troy weight. In the Tower system 1 pennyweight $(\mathrm{dwt})=22 \frac{1}{2}$ grains of barley; $20 \mathrm{dwt}=1 \mathrm{oz}$. The pennyweight was the weight of an English silver penny and is taken in this book as 1.35 grams. Troy weight uses a pennyweight of 24 grains, that is, about 1.56 grams. 